\title{
Utilization of safe male circumcision among adult men in a fishing community in rural Uganda
}

\author{
Mutaawe Lubogo ${ }^{1}$, Ronald Anguzu ${ }^{2}$, Humphrey Wanzira ${ }^{4}$, Abdul R Shour ${ }^{2}$, \\ Aggrey D Mukose ${ }^{1}$, Agnes Nyabigambo ${ }^{3}$, Nazarius M Tumwesigye ${ }^{1}$
}

1. Department of Epidemiology and Biostatistics, School of Public Health, Makerere University, Uganda.

2. Institute of Health and Equity, Medical College of Wisconsin, US.

3. Department of Community Health and Behavioural Sciences, School of Public Health, Makerere University, Uganda.

4. Ministry of Health Headquarters, Uganda.

\section{Email addresses:}

Mutaawe Lubogo: drmutaawe@gmail.com; Ronald Anguzu: ranguzu@mcw.edu; ranguzu@musph.ac.ug; Wanzira Humphrey: wanzirah@yahoo.com; Abdul R Shour: ashour@mcw.edu; Aggrey D Mukose: amukose@musph.ac.ug; Agnes Nyabigambo: agagnesgn95@gmail.com; Nazarius M Tumwesigye: naz@musph.ac.ug

\begin{abstract}
Background: In Uganda, most-at-riskpopulations(MARPs) such as fishing communities remain vulnerable to preventable HIV acquisition. Safe Male Circumcision (SMC) has been incorporated into Uganda's HIV prevention strategies. This study aimed at determining SMC utilization and associated factors among adult men in a rural fishing community in Uganda.

Methods: A cross-sectional study was conducted in a rural fishing village in central Uganda. Stratified random sampling of 369 fishermen aged 18-54 yearswas used according to their occupational category; fish monger, boat crew and general merchandise. The dependent variable wasutilization of SMC.A forward fitting multivariable logistic regression model was fitted with variables significant at $\mathrm{p} \leq 0.05$ controlling for confounding and effect modification.

Results: Respondents'mean(SD) age was 30.0(9.3) years. Only8.4\%hadSMC and among non-circumcised men, 84.9\% had adequate knowledge of SMC benefits while 79.3\% did not know were SMC services were offered.Peer support(AOR0.17;95\%CI0.05-0.60) and perceived procedural safety (AOR6.8;95\%CI2.16-21.17) were independently associated with SMC utilization.

Conclusion: In this rural fishing community, SMC utilization was low. These findings underscore the need to inform HIV preventionstrategies inthecontextof peer support and perceptionsheld by rural dwelling men.
\end{abstract}

Keywords: Safe male circumcision, utilization, fishing community, Most-at-risk populations, Uganda.

DOI: https://dx.doi.org/10.4314/ahs.v19i3.40

Cite as: Lubogo M, Angu₹u R, Wanzira H, Shour AR, Mukose AD, Nyabigambo A, Tumwesigye NM. Utilization of safe male circumcision among adult men in a fishing community in rural Uganda. Afri Health Sci. 2019;19(3): 2645-2653. bttps:/ / dx.doi.org/10.4314/abs.v19i3.40

\section{Background}

Uganda's HIV prevalence rate, at $7.3 \%$, is still one of the highest both in sub-Saharan Africa and globally ${ }^{1}$. According to the United Nations Programme on HIV/ AIDS (UNAIDS), new HIV infections increased from 120,000 to 150,000 between 2004 and 2012 with 62,000 deaths annually attributed to it alone ${ }^{2}$. However, this in-

\section{Corresponding author: \\ Ronald Anguzu, Institute of Health and Equity, \\ Medical College of Wisconsin, US. \\ Email: ranguzu@mcw.edu; ranguzu@musph.ac.ug}

fection rate varies, with some population groups having higher HIV infection and prevalence rates than the general population. Evidence shows that HIV prevalence is six fold higher in fishing communities than in the general population ${ }^{3,4}$. This has been attributed to high risk sexual behaviour, alcohol and drug abuse $e^{5,6}$. Uganda in the early 1990s, adopted the hugely successful strategy of sexual abstinence, being faithful with one partner and to correctly and consistency use condoms or "ABC" to prevent $\mathrm{HIV}^{2}$. This contributed to the reduction of HIV prevalence from $18 \%$ in 1996 to $7.3 \%$ in $2012^{2,7}$. In 2012, Uganda added Safe Male Circumcision (SMC) to the "ABC" strategy in order to reduce this HIV prevalence $^{8,9}$. This was based on findings that showed SMC 
reduced the risk of HIV acquisition among adult males by $60 \%$, in addition to other medical benefits like reduction of sexually transmitted diseases, penile cancer and improvement of penile hygiene ${ }^{2}$. To achieve the required protective effect of SMC, it is estimated that over $80 \%$ of men in the reproductive age should be circumcised ${ }^{10}$.

Currently among reproductive aged Ugandan men, only $25 \%$ have been circumcised ${ }^{9}$, despite evidence which shows that it is highly acceptable ${ }^{11,12}$ and safety of the procedure not only in Uganda ${ }^{13}$ but in other African regions ${ }^{14,15}$. There is paucity of literature, regarding the proportion of adult male saccessing SMC in fishing communities, one of the most-at-risk populations (MARPs) for HIV acquisition. This understanding in addition to the factors associated with having SMC in these communities is important, while developing tailored HIV interventions, especially for MARPS. This study therefore aimed at determining utilization of SMC and other factors associated with SMC by adult men (18-54 years) in a fishing community in a rural district in Uganda.

\section{Methods}

This was a cross-sectional study conducted between March and April 2012, in the only fishing community in Kalungu district. Kalungu district was newly created in 2010 and has a total population of 16,520 people, with only 17 health centres. This site was purposively selected because it has a higher HIV prevalence of $28.8 \%$ compared to Uganda's national average of $7.3 \%$ and is the largest fishing village which is a high-risk population for $\mathrm{HIV}^{16}$. This fishing village has a total population of 1,500 men and 67\% are aged 18-54 years ${ }^{17}$. Most male dwellers are either fish mongers, boat crew or engaged in general merchandise business. The population in this community physically access SMC services from the only Health Centre IV(HCIV) located approximately 10 kilometres away from this fishing village. The resident nurses and physician assistants have been trained by Rakai Health Sciences Program and are World Health Organization (WHO) certified to offer SMC services. The SMC procedure employed by this HCIV is conducted under local anaesthesia, using a penile dorsal slit and is described in detail elsewhere ${ }^{8,18}$.

\section{Sample Size and sampling procedure}

A sample size of 369 respondents was determined using the KishLeslieformula(1965); p of 0.4 , precision of $5 \%$ (margin of error) and a 10\% non-response rate. A sampling frame for all men in each stratum was developed by the investigator team, based on the resident register from the local administration. Based on the three strata of economic activities;118,122 and 129 respondents, that is boat crew, fishmonger and general merchandise trader were selected using probability proportionate-to-size of each stratum. A participant who had been selected to participate in the study and declined was replaced by the next participant who fit the eligibility criteria. The first respondent for the respective occupation categories was selected randomly. The subsequent respondents were consecutively selected until the computed sample sizewas achieved.

\section{Data collection}

Data was collected by use of pre-tested; interviewer administered structured questionnaires with questions on the respondents' age, religion, education level, marital status, occupation, utilizationof SMC, knowledge of SMC benefits and SMC site. Community related variables collected were; partner support, peer support, community leader support, approachable health workers, SMC procedure safety, friendliness and privacy of services.The research assistants were all nurses recruited from health facilities in different neighbouring districts and trained by the investigators for five days on data collection processes. Field editing of collected data was done by field supervisors to check for completeness and accuracy of data.

\section{Study measures}

The dependent variable was utilization of SMC categorized as a binary outcome. Respondents who self-reported being circumcised in a designated health facility for HIV prevention and related health benefits were coded 'Yes' and if otherwise "No". "Peer support" in the Ugandan context refers to relationship in which people view each other as equal partners regarding mutual learning and growth. In this study, peer support was defined as encouragement to take up SMC services by a person of similar HIV status. Theoretically guided by the socio-ecological framework, independent variables included socio-demographic characteristics namely; age, religion, education level,marital and occupation status. Other variables were knowledge of SMC benefits and SMC site. Community-related variables were partner, peer, and community leader support, friendliness and privacy of SMC services, approachability of health workers and safety of SMC procedures. 


\begin{tabular}{|c|c|c|c|}
\hline \multirow[b]{2}{*}{ Variable } & \multicolumn{2}{|c|}{ Outcome: Utilisation of SMC } & \multirow[b]{2}{*}{$\begin{array}{c}\text { Not circumcised, } n=338 \\
n(\%)\end{array}$} \\
\hline & $\begin{array}{c}\text { Total, } N=369 \\
n(\%)\end{array}$ & $\begin{array}{c}\text { Utilized SMC, } \mathrm{n}=31 \\
\mathrm{n}(\%)\end{array}$ & \\
\hline \multicolumn{4}{|l|}{ Age (Years)* } \\
\hline$<20$ & $23(6.2)$ & $1(3.2)$ & $22(6.5)$ \\
\hline $20-29$ & $155(42.0)$ & $19(61.3)$ & $136(40.2)$ \\
\hline $30-39$ & $106(28.7)$ & $6(19.4)$ & $100(29.6)$ \\
\hline $40-49$ & $64(17.4)$ & $4(12.9)$ & $60(17.8)$ \\
\hline$\geq 50$ & $21(5.7)$ & $1(3.2)$ & $20(5.9)$ \\
\hline \multicolumn{4}{|l|}{ Religion } \\
\hline Catholic & $186(50.4)$ & $15(48.4)$ & $171(50.6)$ \\
\hline Protestant & $87(23.6)$ & $8(25.8)$ & $79(23.4)$ \\
\hline Islam $\dagger$ & $96(26.0)$ & $8(25.8)$ & $88(26.0)$ \\
\hline \multicolumn{4}{|l|}{ Education level } \\
\hline None & $42(11.4)$ & $4(12.9)$ & $38(11.2)$ \\
\hline Primary & $245(66.4)$ & $19(61.3)$ & $226(66.9)$ \\
\hline Secondary & $82(22.2)$ & $8(25.8)$ & $74(21.9)$ \\
\hline \multicolumn{4}{|l|}{ Marital status } \\
\hline Single & $118(31.9)$ & $11(35.5)$ & $107(31.7)$ \\
\hline Married & $212(57.5)$ & $18(59.0)$ & $194(57.4)$ \\
\hline Divorced/Separated & $39(10.6)$ & $2(6.5)$ & $37(10.9)$ \\
\hline \multicolumn{4}{|l|}{ Occupation } \\
\hline Fish monger & $122(33.2)$ & $10(32.3)$ & $112(33.1)$ \\
\hline Boat crew & $118(31.9)$ & $11(35.5)$ & $107(31.7)$ \\
\hline General merchandise & 129(34.9) & $10(32.2)$ & $119(35.2)$ \\
\hline \multicolumn{4}{|c|}{ Knowledge of SMC benefits } \\
\hline Yes & $283(76.7)$ & $25(80.6)$ & $287(84.9)$ \\
\hline No & $86(23.3)$ & $6(19.4)$ & $51(15.1)$ \\
\hline \multicolumn{4}{|l|}{ Knowled ge of SMC site } \\
\hline Yes & $106(28.7)$ & $12(38.7)$ & $70(20.7)$ \\
\hline No & $263(71.3)$ & $19(61.3)$ & $268(79.3)$ \\
\hline \multicolumn{4}{|l|}{ Partner encouragement } \\
\hline Yes & 261(70.7) & $25(80.6)$ & $236(69.8)$ \\
\hline No & $108(29.3)$ & $6(19.4)$ & $102(30.2)$ \\
\hline \multicolumn{4}{|l|}{ Peer encouragement } \\
\hline Yes & $234(63.7)$ & $28(90.3)$ & $206(60.9)$ \\
\hline No & $135(36.3)$ & $3(9.7)$ & $132(39.1)$ \\
\hline \multicolumn{4}{|c|}{ Community leader encouragement } \\
\hline Yes & $182(49.5)$ & $18(58.1)$ & 243 (71.9) \\
\hline No & $186(50.5)$ & $13(41.9)$ & $95(28.1)$ \\
\hline \multicolumn{4}{|l|}{ Friendly services } \\
\hline Yes & $271(73.4)$ & $29(93.5)$ & $242(71.6)$ \\
\hline No & $98(26.6)$ & $2(6.5)$ & $96(28.4)$ \\
\hline \multicolumn{4}{|l|}{ Privacy of services } \\
\hline Yes & $330(89.4)$ & $26(83.9)$ & $304(89.9)$ \\
\hline No & $39(10.6)$ & $5(16.1)$ & $34(10.1)$ \\
\hline \multicolumn{4}{|c|}{ Approachable health workers } \\
\hline Yes & $315(85.4)$ & $26(83.9)$ & $289(85.5)$ \\
\hline No & $54(14.6)$ & $5(16.1)$ & $49(14.5)$ \\
\hline \multicolumn{4}{|l|}{ Safety of SMC procedure } \\
\hline Yes & $209(56.6)$ & $27(87.1)$ & $182(53.8)$ \\
\hline No & $160(43.4)$ & $4(12.9)$ & $156(46.2)$ \\
\hline
\end{tabular}

\section{Data analysis}

Double data entry and cleaning were done in Epi info 3.5.1 and then exported to SSTATA/SE12. software package for statistical analysis. Descriptive analysis was conducted for the independent variables. Socio-demographic characteristics were analysed and reported using frequencies and percentages respectively. The level of utilization of SMC by men in the fishing community was presented as percentages with their respective $95 \%$ confidence intervals. Partner and peer support as well as community-related factors were also presented as percentages. For factors associated with SMC use, we run a forward fitting multivariable logistic regression model toestimate the crude (COR) and adjusted (AOR) odds ratio, with their $95 \%$ confidence intervals $(\mathrm{CI})$ and $\mathrm{p}$-values. In all analyses, a $\mathrm{p} \leq 0.05$ was considered significant.

\section{Ethics}

Ethical approval to conduct this study was obtained from Makerere University School of Public Health Higher De- 
gree Research and Ethics Committee. Privacy and confidentiality of respondent information was upheld by the research team. Respondent anonymity was observed through use of questionnaire identification numbers. All study respondents were 18 years and above and offered verbal and written informed consent before inclusion into the study. Local authority permission to conduct this study in this fishing village was obtained from Kalungu district administration and beach management unit.

\section{Results}

\section{Respondent description}

Overall, 369 men were enrolled in the study with a mean age of 30 years (9.3 SD). Half of the respondents were Roman Catholic, $66.4 \%$ had attained primary education and $57.5 \%$ were currently married. Nearly one third of all the respondent's occupation was either; general merchandise (35\%), fish mongers $(33.1 \%)$ or boat crew (32\%) strata. Among non-circumcised men, the majority $(84.9 \%)$ had adequate knowledge of SMC benefits while $79.3 \%$ did not know where SMC services were offered in Kalungu district (Table 1).

\section{Utilisation of safe male circumcision and associated} factors

Further data analysis showed that only 31 (8.40\%,95\%CI 5.56-11.24) of 369 male respondents had been circumcised in a SMC designated health facility (Table 1). Among respondents who utilized SMC, the majority (61.3\%) were aged 20-29 years and Catholic (48.4\%). Still among respondents who utilized SMC, most had attained primary education (61.3\%) and were currently married (59.0\%).

Most respondents who utilized SMC (80.6\%) had adequate knowledge of the benefits of SMC. However, most men who had SMC (61.3\%) did not know the SMC designated health unit in Kalungu district (Table 1). Among non-users of SMC, only $20.7 \%$ had knowledge of the SMC site.

Adult men in this fishing community who had no knowledge of SMC benefits were $79 \%$ less likely to utilize SMC services compared to those with adequate knowledge on SMC services (OR 0.21 95\%CI 0.05-0.89) (Table 2). Age, education level, marital status and occupation of these adult men were not significantly associated with SMC utilization at bivariate analysis (Table 2). Nine out of ten adult men who used SMC services received peer support $(90.3 \%)$ and $93.5 \%$ perceived SMC services provided as being friendly. Four fifths $(87.1 \%)$ of adult men in this fishing village perceived SMC procedures to be safe.

Adult men who did not receive peer support were $80 \%$ less likely to utilize SMC services compared to those who received peer support (COR 0.2; 95\% CI 0.05-0.60). Adult men who perceived the SMC procedure as safe were six times more likely to use SMC services compared to adult men who perceived SMC to be unsafe (COR 5.79; 95\%CI 1.94-17.24). Adult men who did not perceive SMC services as friendly were $83 \%$ less likely to use SMC compared those did not perceive them as being friendly (COR 0.17; 95\%CI 0.004-0.75) (Table 2). 


\begin{tabular}{|c|c|c|}
\hline \multicolumn{3}{|c|}{ Outcome: Utilisation of SMC } \\
\hline Variable & Crude OR $(95 \% \mathrm{Cl})$ & Adj. OR (95\% Cl) \\
\hline \multicolumn{3}{|l|}{ Age (years) } \\
\hline$<20$ & 1 & 1 \\
\hline $20-29$ & $3.07(0.39-24.13)$ & $2.92(0.34-25.27)$ \\
\hline $30-39$ & $1.32(0.15-11.52)$ & $1.20(0.11-12.56)$ \\
\hline $40-49$ & $1.47(0.16-13.85)$ & $1.38(0.12-15.64)$ \\
\hline$\geq 50$ & $1.10(0.06-18.77)$ & $1.64(0.08-34.60)$ \\
\hline \multicolumn{3}{|l|}{ Marital status } \\
\hline Never married & 1 & 1 \\
\hline Currently married & $0.90(0.41-1.98)$ & $0.98(0.39-2.43)$ \\
\hline Separated/Widow/divorced & $0.61(0.13-2.89)$ & $0.95(0.17-5.15)$ \\
\hline \multicolumn{3}{|l|}{ Education level } \\
\hline None & 1 & 1 \\
\hline Primary & $0.80(0.26-2.48)$ & $0.67(0.20-2.25)$ \\
\hline Secondary ${ }^{\dagger}$ & $1.04(0.29-3.68)$ & $0.65(0.17-2.52)$ \\
\hline \multicolumn{3}{|l|}{ Occupation } \\
\hline Fish monger & 1 & 1 \\
\hline Boat crew & $1.15(0.45-2.82)$ & $1.39(0.54-3.62)$ \\
\hline General merchandise & $0.94(0.38-2.35)$ & $1.06(0.40-2.77)$ \\
\hline \multicolumn{3}{|l|}{ Peer encouragement } \\
\hline Yes & 1 & 1 \\
\hline No & $0.17(0.05-0.56)$ & $* * 0.17(0.05-0.60)$ \\
\hline \multicolumn{3}{|l|}{ Partner encouragement } \\
\hline Yes & 1 & 1 \\
\hline No & $0.56(0.26-1.78)$ & $0.69(0.26-1.78)$ \\
\hline \multicolumn{3}{|l|}{ Knowledge of SMC benefits } \\
\hline Yes & 1 & 1 \\
\hline No & $0.21(0.05-0.89)$ & $0.76(0.34-1.73)$ \\
\hline \multicolumn{3}{|l|}{ Safety of SMC procedure } \\
\hline No & 1 & 1 \\
\hline Yes & $5.79(1.98-16.89)$ & $* * 6.80(2.16-21.17)$ \\
\hline \multicolumn{3}{|l|}{ Friendly services } \\
\hline Yes & 1 & 1 \\
\hline No & $0.17(0.04-0.74)$ & $1.90(0.21-17.81)$ \\
\hline
\end{tabular}

After adjusting for confounding at multivariable analysis (Table 2); men without peer support had 85\% reduced odds of using SMC services compared to those with peer support (AOR 0.15; 95\%CI 0.06-0.66). Men who perceived SMC procedure as safe had seven times increased odds of utilizing SMC compared to those who did not perceive SMC procedures as safe (AOR 6.8; 95\%CI 1.73$51.38)$.

\section{Discussion}

The aim of this study was to determine utilization of SMC and factors associated with SMC use among adult men in a rural fishing community in Uganda. Our study found that the proportion of adult men in this fishing community utilising SMC was $8.4 \%$. This is ten foldless than the $80 \%$ coverage recommended to achieve a 30 to $50 \% \mathrm{HIV}$ incidence reduction ${ }^{19}$. Among adult males that utilised SMC in this fishing population, the proportionsfor SMC among the three occupational strata were comparable.

Previous studies in Uganda showedmuchhigher SMC utilisationin fishing villages on Lake Victoria and semi-rural settings ${ }^{20,21}$. These differences could be due to the po- 
tential effect of intensive pre-existing SMC activities and physical access to SMC designated health facilities in the other studies. Findings from South Africa revealed relatively higher SMC utilization contrary to ours ${ }^{22}$. Smaller sample size and rural-urban differences could have contributed to differences with our findings. Withonly one SMC site, this fishing population has limited physical access to SMC services. Negative perceptions towards SMC providers despite knowledge of SMC benefits could alsohave contributed to low SMC use in this fishing village.Previous studies suggest that fishing villages usually have poor physical access to SMC health units and no availability of static SMC services ${ }^{6,23}$. In addition, other barriers to SMC include traditional or cultural institutions that practice male circumcision which could be impeding SMC goals or potential for success.

From the time this study was conducted, there has been an increase in the coverage of SMC services as part of the combined HIV strategy in Uganda, leading to a higher proportion of circumcised men in fishing communities $^{24}$. This increase is important as it demonstrates the strengthening of HIV service prevention strategies in these settings, including SMC, with our study estimating a baseline to quantify this success ${ }^{25}$.

Our study revealed that peer support and perceptions of procedural safety influenced SMC use among adult men. This conformed with evidence from Uganda and Tanzania were peer influence motivated medical male circumci$\operatorname{sion}^{26,27}$. Other findings show that peergroups in Kenya, generally accepted in African communities as social support groups were key in mobilization of men for SMC uptake ${ }^{28}$.

This study showed that circumcised peers encouraged friends to be circumcised in medical settings. Peers provide the required confidence in such circumstances ${ }^{29,30}$. Stillinfishing settingsinUganda,otherfindingsshowedthatthemajority ofmenrely ontheirpeersfor thiskindofsupport $^{23}$. Decision making for SMC utilization is important for use of reproductive health services like family planning $^{31}$ and antenatal care . $^{32}$.

In our study, perceived safety of SMC procedures was a key factor in the utilization of SMC. Another study in Uganda suggested that perceived safety of safe male cir- cumcision operations by skilled health workers encourages SMC use ${ }^{33}$. Previous studies in sub-Saharan Africa showed that the majority perceived the SMC technique as safe, compared to other modes of circumcision ${ }^{34-36}$. This is because SMC is provided by trained health workers and the procedure is performed in hygienic conditions reducing the rates of post circumcision complications ${ }^{37}$. Evidence from South Africa, Botswana and Tanzania suggest thatcreating friendly relationshipswasimportantinimprovingtheutilizationofhealthservices ${ }^{38-40}$. Contrary to our findings, other studies on male circumcision shows that religion and education affect its utilization ${ }^{41,42}$. These factors identified are still applicable in our setting as shown by evidence from other studies ${ }^{43}$.

However, the notion of perceived safety could be contested. Targeted populations may not consider safety as a primary factor because most traditional doctors that perform circumcision at the local level, are not medically trained, nor are their practices completely hygienic or safe.But these do not stop men from utilizing these local services. The point is that safety is a relative term which could mean different things to peoplewith diverse cultural orientations. Cultural reasons play a key role in decision-making relating to utilization. Local circumcisions are carried out to establish manhood, prepare for marriages, demand respect among peers, and to avoid stigma from family and peers.In some African settings such as the Poro society in Sierra Leone, men undergo circumcision not because of safety reasons or concerns but mainly due to traditional reasons such as initiation into manhood for societal recognition, or identity. These are some of the factors that could be incorporated in policy development to increase access to SMC utilization.

In terms of our study limitations, these findings should be interpreted with caution. First, this study did not have a qualitative component for triangulation of the perceptions of men towards SMC. Secondly, these findings are not being generalizable to the general population but to fisherfolk communities in central Uganda. Thirdly, this study reported SMC use in this fishing community four years ago which could have been overtaken by events. In addition, no follow-up study has been conducted yet which limits comparison with more recent events.Previous studies on SMC in fishing communities have been conducted in districts neighbouring our study area ${ }^{44,45}$. 
However, in the context of Kalungu with a fourfold HIV prevalence compared to the national level, these findings may inform stakeholders involved in HIV prevention activities. Response bias could have arisen due to self-reporting of circumcision status. Misclassification bias could have arisen were circumcision conducted in an SMC designated health unit outside the study area is categorized as non-SMC use. These limitations were addressed by using detailed probe questions about the health facility accessed for SMC. Women and spouses to men in this fishing community were excluded though evidence asserts the significance of spousal involvement in the utilization of SMC services ${ }^{46}$.

We however probed respondents whether their spouses encouraged them to be circumcised in the medical setting. Future studies may explore cultural and health system barriers and opportunities for SMC use in settings with low safe male circumcision uptake.In addition, future research investigating the role of peer support on SMC use may apply, test or be informed by behavioural theories of social support or social networks.

\section{Author contribution}

ML was the principal investigator, conceived the original research idea and developed the protocol. ADM and NMT revised the methodology and mentored the author. WH conducted the statistical analysis. RA, ML, WH, ARS and $\mathrm{AN}$ drafted and supervised manuscript development. All authors read and approved the final manuscript.

\section{Acknowledgements}

Appreciation goes to the supervisors for the work done to develop the manuscript. The authors received no funding to conduct this study.

\section{Conflict of interest}

None declared.

\section{References}

1. HIV/AIDS JUNP on. Global Report: UNAIDS Report on the Global AIDS Epidemic 2013. Unaids; 2013.

2. Health UM of, (Firm) ICFI. Uganda AIDS Indicator Survey 2011. ICF International; 2012.

3. Asiki G, Mpendo J, Abaasa A, et al. HIV and syphilis prevalence and associated risk factors among fishing communities of Lake Victoria, Uganda. Sex Transm Infect. 2011. doi:10.1136/sti.2010.046805.

4. Kiwanuka N, Ssetaala A, Mpendo J, et al. High HIV1 prevalence, risk behaviours, and willingness to participate in HIV vaccine trials in fishing communities on Lake Victoria, Uganda. J Int AIDS Soc. 2013. doi:10.7448/ IAS.16.1.18621.

5. Seeley J, Nakiyingi-Miiro J, Kamali A, et al. High HIV incidence and socio-behavioral risk patterns in fishing communities on the shores of Lake Victoria, Uganda. Sex Transm Dis. 2012. doi:10.1097/OLQ.0b013e318251555d. 6. Tumwesigye NM, Atuyambe L, Wanyenze RK, et al. Alcohol consumption and risky sexual behaviour in the fishing communities: Evidence from two fish landing sites on Lake Victoria in Uganda. BMC Public Health. 2012. doi:10.1186/1471-2458-12-1069.

7. UBOS and ICF. Uganda Demograpic and Health Survey 2011.; 2012.

8. Gray RH, Kigozi G, Serwadda D, et al. Male circumcision for HIV prevention in men in Rakai, Uganda: a randomised trial. Lancet. 2007. doi:10.1016/S01406736(07)60313-4.

9. MoH. Safe Male Circumcision Policy.; 2010.

10. Njeuhmeli E, Forsythe S, Reed J, et al. Voluntary medical male circumcision: Modeling the impact and cost of expanding male circumcision for HIV prevention in Eastern and Southern Africa. PLoS Med. 2011. doi:10.1371/journal.pmed.1001132.

11. Kigozi G, Musoke R, Watya S, et al. The acceptability and safety of the Shang Ring for adult male circumcision in Rakai, Uganda. J Acquir Immune Defic Syndr. 2013. doi:10.1097/QAI.0b013e3182968dda.

12. Wambura M, Mwanga JR, Mosha JF, Mshana G, Mosha F, Changalucha J. Acceptability of medical male circumcision in the traditionally circumcising communities in Northern Tanzania. BMC Public Health. 2011. doi:10.1186/1471-2458-11-373.

13. Buwembo DR, Musoke R, Kigozi G, et al. Evaluation of the safety and efficiency of the dorsal slit and sleeve methods of male circumcision provided by physicians and clinical officers in Rakai, Uganda. BJU Int. 2012. doi:10.1111/j.1464-410X.2011.10259.x.

14. Westercamp N, Bailey RC. Acceptability of male circumcision for prevention of HIV/AIDS in sub-Saharan Africa: A review. AIDS Behav. 2007. doi:10.1007/s10461006-9169-4. 
15. Lagarde E, Dirk T, Puren A, Reathe RT, Bertran A. Acceptability of male circumcision as a tool for preventing HIV infection in a highly infected community in South Africa. AIDS. 2003. doi:10.1097/00002030200301030-00012.

16. Mutaawe Master of public health A. Utilisation of safe male circumcision services by men aged 18-54 years in fishing communities in Kalungu district, Uganda. $20^{\text {th }}$ Int AIDS Conf. July 20-25, 2014, Melbourne, Aust. 2014. 17. UBOS. National Population and housing Census. Uganda Bur Stat. 2006.

18. WHO. Manual for Male Circumcision under Local Anaesthesia.; 2009.

19. UNAIDS. How to Get to Zero: Faster. Smarter. Better. UNAIDS World AIDS Day Report.; 2011. doi:ISBN: 978-92-9173-904-2 | UNAIDS / JC2216E.

20. Opio A, Muyonga M, Mulumba N. HIV Infection in Fishing Communities of Lake Victoria Basin of Uganda -A Cross-Sectional Sero-Behavioral Survey. PLoS One. 2013. doi:10.1371/journal.pone.0070770.

21. Mukama T, Ndejjo R, Musinguzi G, Musoke D. Perceptions about medical male circumcision and sexual behaviours of adults in rural Uganda: A cross sectional study. Pan AfrMedJ.2015. doi:10.11604/pamj.2015.22.354.7125. 22. Hoffman JR, Arendse KD, Larbi C, Johnson N, Vivian LMH. Perceptions and knowledge of voluntary medical male circumcision for HIV prevention in traditionally non-circumcising communities in South Africa. Glob Public Health. 2015. doi:10.1080/17441692.2015.1014825.

23. Seeley JA, Allison EH. HIV/AIDS in fishing communities: Challenges to delivering antiretroviral therapy to vulnerable groups. AIDS Care - Psychol Socio-Medical Asp AIDS/HIV. 2005. doi:10.1080/09540120412331336698. 24. Grabowski MK, Serwadda DM, Gray RH, et al. Combination HIV prevention and HIV incidence in Uganda. N Engl J Med. 2017.

25. Grabowski MK, Serwadda DM, Gray RH, et al. HIV prevention efforts and incidence of HIV in Uganda. $N$ Engl J Med. 2017;377(22):2154-2166.

26. Evens E, Lanham M, Hart C, Loolpapit M, Oguma I, Obiero W. Identifying and addressing barriers to uptake of voluntary medical male circumcision in Nyanza, Kenya among men 18-35: A qualitative study. PLoS One. 2014. doi:10.1371/journal.pone.0098221.

27. Ssekubugu R, Leontsini E, Wawer MJ, et al. Contextual barriers and motivators to adult male medical circumcision in Rakai, Uganda. Qual Health Res. 2013. doi: $10.1177 / 1049732313482189$

28. Herman-Roloff A, Otieno N, Agot K, Ndinya-Achola J, Bailey RC. Acceptability of medical male circumcision among uncircumcised men in Kenya one year after the launch of the national male circumcision program. PLoS One. 2011. doi:10.1371/journal.pone.0019814.

29. Rawal LB, Wolfe R, Joyce C, et al. Utilisation of general practitioner services and achievement of guideline targets by people with diabetes who joined a peer-support program in Victoria, Australia. Aust J Prim Health. 2015. doi:10.1071/PY13178.

30. Dyc NG, Pena ME, Shemes SP, Rey JE, Szpunar SM, Fakih MG. The effect of resident peer-to-peer education on compliance with urinary catheter placement indications in the emergency department. Postgrad Med J. 2011. doi:10.1136/postgradmedj-2011-130287.

31. Anguzu R, Tweheyo R, Sekandi JN, et al. Knowledge and attitudes towards use of long acting reversible contraceptives among women of reproductive age in Lubaga division, Kampala district, Uganda. BMC Res Notes. 2014. doi:10.1186/1756-0500-7-153.

32. Tweheyo R, Konde-Lule J, Tumwesigye NM, Sekandi JN. Male partner attendance of skilled antenatal care in peri-urban Gulu district, Northern Uganda. BMC Pregnancy Childbirth. 2010. doi:10.1186/1471-2393-10-53.

33. Muhamadi L, Ibrahim M, Wabwire-Mangen F, Peterson S, Reynolds SJ. Perceived medical benefit, peer/ partner influence and safety and cost to access the service: Client motivators for voluntary seeking of medical male circumcision in Iganga District Eastern Uganda, a qualitative study. Pan Afr Med J. 2013. doi:10.11604/ pamj.2013.15.117.2540.

34. Kigozi G, Gray RH, Wawer MJ, et al. The safety of adult male circumcision in HIV-infected and uninfected men in Rakai, Uganda. PLoS Med. 2008. doi:10.1371/ journal.pmed.0050116.

35. Kigozi G, Musoke R, Kighoma N, et al. Safety of medical male circumcision in human immunodeficiency virus-infected men in Rakai, Uganda. Urology. 2014. doi:10.1016/j.urology.2013.08.038.

36. Lebina L, Milovanovic M, Tshabangu NC, Tarabureka N, Martinson N, Manentsa M. Assessing the Acceptability of the PrePexTM Device for Voluntary Medical Male Circumcision in South Africa. AIDS Res Hum Retroviruses. 2014. doi:10.1089/aid.2014.5426.abstract.

37. Kigozi G, Musoke R, Kighoma N, et al. Male circumcision wound healing in human immunodeficiency virus 
(HIV)-negative and HIV-positive men in Rakai, Uganda. BJU Int. 2014. doi:10.1111/bju.12406.

38. Alli F, Maharaj P, Vawda MY. Interpersonal relations between health care workers and young clients: Barriers to accessing sexual and reproductive health care. J Community Health. 2013. doi:10.1007/s10900-012-9595-3.

39. Lesedi C, Hoque ME, Ntuli-Ngcobo B. Investigating user-friendliness of the sexual and reproductive health services among youth in Botswana. Southeast Asian J Trop Med Public Health. 2011.

40. Mbeba RM, Mkuye MS, Magembe GE, Yotham WL, Mellah AO, Mkuwa SB. Barriers to sexual reproductive health services and rights among young people in Mtwara district, Tanzania: a qualitative study. Pan Afr Med J. 2012. 41. Ladizinski B, Rukhman E, Lee KC. Male Circumcision as a Religious Ritual. JAMA Dermatology. 2014. doi:10.1001/jamadermatol.2013.8367.

42. Walcott MM, Jolly PE, Ehiri JE, et al. Factors Associated with the Acceptability of Male Circumcision among Men in Jamaica. PLoS One. 2013. doi:10.1371/journal. pone. 0075074 .
43. Monroe A, Nakigozi G, Ddaaki W, et al. Qualitative insights into implementation, processes, and outcomes of a randomized trial on peer support and HIV care engagement in Rakai, Uganda. BMC Infect Dis. 2017;17(1):54. 44. Nevin PE, Pfeiffer J, Kibira SPS, Lubinga SJ, Mukose A, Babigumira JB. Perceptions of HIV and safe male circumcision in high HIV prevalence fishing communities on lake Victoria, Uganda. PLoS One. 2015. doi:10.1371/ journal.pone. 0145543 .

45. Sileo KM, Kintu M, Chanes-Mora P, Kiene SM. "Such Behaviors Are Not in My Home Village, I Got Them Here": A Qualitative Study of the Influence of Contextual Factors on Alcohol and HIV Risk Behaviors in a Fishing Community on Lake Victoria, Uganda. AIDS Behav. 2016. doi:10.1007/s10461-015-1077-z.

46. Hatzold K, Mavhu W, Jasi P, et al. Barriers and motivators to voluntary medical male circumcision uptake among different age groups of men in Zimbabwe: Results from a mixed methods study. PLoS One. 2014. doi:10.1371/journal.pone.0085051. 